RESEARCH NOTE

\title{
Is it time to leave behind the Revised Hierarchical Model of bilingual language processing after fifteen years of service?
}

\author{
MARC BRYSBAERT \\ Ghent University, Belgium and Royal Holloway, \\ University of London \\ WOUTER DUYCK \\ Ghent University, Belgium
}

(Received: 18 February 2009; Revised: 25 August 2009; Accepted: 15 September 2009; First published online 29 January 2010)

\begin{abstract}
The Revised Hierarchical Model (RHM) of bilingual language processing dominates current thinking on bilingual language processing. Recently, basic tenets of the model have been called into question. First, there is little evidence for separate lexicons. Second, there is little evidence for language selective access. Third, the inclusion of excitatory connections between translation equivalents at the lexical level is likely to impede word recognition. Fourth, the connections between L2 words and their meanings are stronger than proposed in RHM. And finally, there is good evidence to make a distinction between language-dependent and language-independent semantic features. It is argued that the Revised Hierarchical Model cannot easily be adapted to incorporate these challenges and that a more fruitful way forward is to start from existing computational models of monolingual language processing and see how they can be adapted for bilingual input and output, as has been done in the Bilingual Interactive Activation model.
\end{abstract}

Bilingualism is a ubiquitous phenomenon, particularly among people who do not belong to an economically dominant group (Myers-Scotton, 2006). For a long time, psycholinguistic research on bilingualism was restricted because researchers were only interested in the rare cases of balanced bilinguals, who had acquired both languages very early in life (simultaneous acquisition) and were able to use them interchangeably. Other language researchers were not interested in bilingualism because they assumed that native language (L1) processing was not influenced by the knowledge of a second language (L2), and hence that it did not matter whether their participants were monolingual or bilingual. In recent years the situation has changed dramatically, both because researchers became interested in the much wider group of unbalanced bilinguals who learned a second language in school (sequential acquisition), and because researchers started to realize that knowledge of L2 has an impact on L1 processing (see below).

In 1994, Kroll and Stewart published a model that would take a central position in research on bilingualism, and which is the topic of the present review. First we present the model and some evidence for it. Then we focus on some shortcomings that have been revealed in the fifteen years since the model's introduction, and we end by calling for an alternative approach. Because the model deals only with word processing, our review will be limited to this topic.

\section{The Revised Hierarchical Model}

On the basis of a review of the available literature and new empirical research, Kroll and Stewart (1994) proposed a general model of bilingual language processing, the so-called Revised Hierarchical Model (RHM; Figure 1). Although the model could be applied to simultaneously acquired languages, it was mainly inspired by sequential language acquisition, with L2 learning taking place after L1 has been mastered to a considerable degree.

According to the Revised Hierarchical Model, a hierarchical distinction had to be made between two types of word representations: lexical representations containing information about word FORMS, and conceptual representations corresponding to the word MEANINGS. At the lexical level, a division was made between a lexicon for the native language and a lexicon for the second known language. Because bilinguals know more words in L1 than in L2, the L1 lexicon was hypothesized to be larger than the L2 lexicon. The conceptual level was assumed to be shared by the two languages.

Probably the most important feature of the model involved the interactions between the various components. RHM introduced a combination of two previously suggested organizations: One in which L2 words were recognized by direct lexical associations with their L1 translations (the Word Association model) and one in which L2 words, just like L1 words, made direct

Address for correspondence:

Marc Brysbaert, Department of Experimental Psychology, Ghent University, Henri Dunantlaan 2, B-9000 Gent, Belgium

marc.brysbaert@ugent.be 


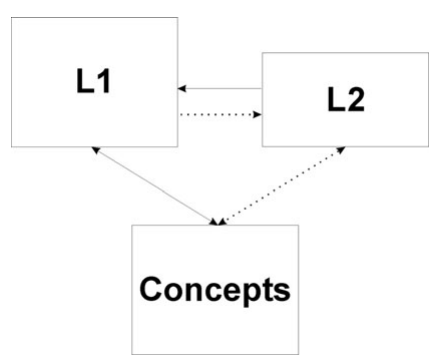

Figure 1. Kroll and Stewart's (1994) Revised Hierarchical Model. The RHM makes a distinction between a lexical and a conceptual level. At the lexical level, two lexicons are distinguished: one for words of the mother tongue (L1) and one for words of another known language (L2). Translation equivalents in the different lexicons are connected to each other by excitatory links. Certainly, in the early stages of language proficiency, the links are assumed to be much stronger from L2 to L1 than vice versa, as many L2 words are learned by associating them with their L1 translation. The two lexicons are connected to a shared conceptual system that contains the meaning of the words. Connections between L1 words and concepts are thought to be stronger than those between L2 words and concepts.

connections to the conceptual system (the Concept Mediation model). In the Revised Hierarchical Model, both types of connections were present, but with different strengths for L1 and L2. The connections between the L1 lexicon and the conceptual system were stronger than those between the L2 lexicon and the conceptual system. In contrast, the word-word associations from L2 to L1 were stronger than those from L1 to L2 (because L2 words are usually learned by associating them with their L1 translations).

\section{Contributions of the Revised Hierarchical Model}

The Revised Hierarchical Model has been very influential because it offered researchers a useful framework for understanding the main issues in bilingual language processing. Four contributions stand out, and are discussed below.

\section{The separation of lexical and conceptual representations}

One of the main discussions in early research on bilingualism was whether the bilingual's two languages were shared or separated. Some evidence pointed towards shared representations. For instance, Glanzer and Duarte (1971; see also Heredia, 2008, for a summary) asked Spanish-English bilinguals to memorize lists of Spanish and English words. Some words were presented twice in the list, either in the same language (e.g., house,..., house) or in different languages (e.g., house,..., casa). The authors observed that repeated words were remembered better than non-repeated words, both for within-language repetitions and between-language repetitions (in the latter case the performance even exceeded that of the within-language stimuli if the number of intervening stimuli between the two targets was two or less). Glanzer and Duarte (1971) interpreted this finding as evidence for shared representations.

Other evidence, however, pointed toward separate representations. Goggin and Wickens (1971; see also Heredia, 2008), for instance, investigated the proactive interference effect within and across languages. The proactive interference effect refers to the fact that participants find it harder to memorize stimuli if they learned other stimuli of the same category before. Typically, fewer items are recalled from the list apple, grape, orange, apricot if the list peach, cherry, plum, pineapple was learned previously than if the list arm, eye, finger, head was learned. Goggin and Wilkins observed that the proactive interference effect was significantly reduced if bilingual participants switched languages between the lists, suggesting that fluent bilinguals were able to store information in two distinct codes/representations.

Because the RHM separated lexical and conception representations into distinct levels, it offered a good explanation for the early and conflicting evidence. The model predicted that whenever a task involved the form properties of the words (the lexical level), it would provide evidence in line with distinct representations. In contrast, if a task tapped into the meaning of the words, it would produce evidence in favor of a common structure. The RHM was not the first to propose a hierarchical organization of the lexical and the conceptual level (hence the name REvised Hierarchical Model), but it was the first to clearly outline the implications of the hierarchical model for the issue of shared vs. separate representations in bilingual language processing.

\section{Separate lexicons and selective access}

A second interesting aspect of RHM was that it made a distinction between the L1 and the L2 lexicon. Although this was not emphasized in Kroll and Stewart's (1994) text (nor in any later papers on the model by Kroll), some of the attraction of the RHM was that it seemed to support earlier, intuitively plausible views that considered bilingualism as the coexistence of two largely independent language systems. Given that there were two distinct lexicons, it seemed plausible to assume that the model also included selective access to one or the other lexicon. According to the selective access view, bilinguals can inhibit or activate one of their languages, depending on the context (see van Heuven, Dijkstra and Grainger (1998) for a discussion of the different possible organizations of a bilingual word recognition system). So, a person 
processing words in L1 could deactivate (or inhibit) the L2 lexicon. Similarly, a proficiently bilingual person processing words in L2 could be regarded as having the L1 lexicon switched off. Because such an organization provided a straightforward "account" of why bilinguals do not show much interference from the other language while they are processing one language, the RHM was attractive to those researchers who saw selective access as a means of language control in bilinguals (see Green (1998), and the special issue of Bilingualism: Language and Cognition (2006, 9 (2)), for more elaborated discussions on the issue of language control in bilingual speech).

\section{Asymmetries between $L 1$ and $L 2$ processing}

The RHM also offered interesting hypotheses about the ways in which L1 and L2 processing diverged. Two aspects have been particularly appealing. The first is the conjecture that semantic information is easier to access from L1 input. The second is the speculation that nonsemantic word-word associations are more important for L2 word recognition than L1 word recognition. As a matter of fact, much of the Kroll and Stewart (1994) paper was devoted to these asymmetries. The empirical evidence centered on the finding that pictures are named more slowly when they appear among other pictures of the same category than when they appear among pictures of other categories, suggesting some sort of semantic interference effect. The first two experiments reported by Kroll and Stewart validated the existence of such a category interference effect (later replicated, among others, by Damian, Vigliocco and Levelt, 2001, and Belke and Meyer, 2005). Crucially, the third experiment showed that the category interference effect was only present for word translation in the L1-L2 direction and not in the L2L1 direction, in line with the hypothesis that "for relatively fluent but unbalanced bilinguals, there is an asymmetry between the two directions of translation that reflects differential reliance on lexical and conceptual activation during the translation process" (Kroll and Stewart, 1994, p. 168).

Further arguments for a smaller involvement of meaning in L2 word processing were sought in the literature on cross-language semantic priming. If participants could rely less on meaning to process L2 words, then more priming is expected from L1 to L2 (e.g., for a Dutch-English bilingual from the prime meisje "girl" to the target boy) than from L2 to L1 (from the prime girl on the target jongen "boy"). Kroll and Stewart (1994) listed evidence along these lines by Altarriba (1990) and Keatley, Spinks and de Gelder (1994); they also referred to an unpublished study by Kroll and colleagues. As we will see below, further research has indeed confirmed and extended the asymmetry in semantic priming between forward translation (from L1 to L2) and backward translation (from L2 to L1).

Evidence for the strong word-word connections in the L2-L1 direction was found in the observation that translation from L2 to L1 was much faster (199 ms; Kroll and Stewart, 1994) than translation from L1 to L2. The extra time needed for forward translation was particularly high when words of the same category had to be translated. Backward translation was much less influenced by the category interference effect, in line with the suggestion that this type of translation relied more on word-word associations than on conceptual mediation.

\section{The developmental aspect of bilingualism}

Finally, the RHM appealed to many researchers in language acquisition because it included an interesting view of how the organization of bilingual memory changed as a function of increasing proficiency. The idea was that in the very first stages of L2 acquisition, only the associations between the newly learned L2 words and their L1 translations were made. Gradually, as proficiency increased, the links between L2 words and conceptual information developed, so that for a very proficient L2 speaker the links between the L2 lexicon and the conceptual system were (almost) as strong as those between the L1 lexicon and the conceptual system.

Kroll and de Groot (1997) listed several pieces of evidence for the developmental hypothesis. For instance, they pointed to the big advantage of cognates in early phases of L2 learning. Cognates are translation equivalents in two languages with the same or a very similar form (e.g., the English-French word pair tomatotomate). According to Kroll and de Groot (1997), because of their form overlap cognates are easy to associate at the lexical level. Conversely, beginning L2 learners have problems deciding that two words are not each other's translation if one of the words resembles the translation to a large degree (e.g., unbalanced EnglishSpanish bilinguals find it difficult to decide that hambre "hunger" is not a translation of man because of the high orthographic overlap with the true translation hombre).

\section{An example of the impact of RHM: neurocognition}

The impact of RHM can be illustrated by looking at the ways in which it has inspired research on the neural mechanisms of bilingual language processing. Already before the publication of the model, neuropsychological findings provided input to the debate of how the bilingual brain is organized. For instance, reviews of the neuropsychological literature had indicated that aphasia as a result of right hemisphere damage was not more prevalent among bilinguals than among monolinguals and not more frequent for L2 than for L1, refuting the 
possibility that the separation of the L1 and L2 lexicons could be explained by assuming a more right hemisphere lateralization of the L2 lexicon (e.g., Paradis, 1990).

A similar conclusion was reached after the first brain imaging studies. For the vast majority of bilinguals, L2 processing, just like L1 processing, is left lateralized. As a matter of fact, L2 processing makes use of very much the same brain areas as $\mathrm{L} 1$ processing. The most frequently reported difference between $\mathrm{L} 2$ and $\mathrm{L} 1$ processing is that L2 processing recruits extra brain areas, in particular at rather low proficiency levels (see Indefrey, 2006, for a meta-analysis). Occasionally, more activity for L1 processing in a particular brain area is reported. For instance, in the six studies on word comprehension reviewed by Indefrey (2006, p. 287, Table 1, section "Semantic decision on written words"), one study with highly proficient bilinguals (all late learners) found no significant differences between L1 and L2, two studies with moderately to highly proficient bilinguals found more activity in the left middle temporal gyrus for decisions on L1 words, and three studies with less proficient bilinguals reported more activity for L2 words in several left frontal and parietal areas. All these areas are known to be involved in semantic decisions. Both the differences between L1 and L2 processing and the increasing convergence between $\mathrm{L} 1$ and $\mathrm{L} 2$ processing with greater L2 proficiency have been interpreted in line with the RHM framework.

At the same time, the brain imaging studies made clear that the extra activity observed in bilingual language processing mainly involved control processes rather than language processing. In a review of the literature on language production, Abutalebi and Green (2007) pointed out that a network of structures related to cognitive control tends to be active when bilinguals speak one of their languages, translate words or switch languages. This network includes the prefrontal cortex (involved in executive functions, decision-making, response selection, response inhibition and working memory), the anterior cingulate cortex (involved in attention, conflict monitoring and error detection), the basal ganglia (involved in language selection, set switching, language planning and lexical selection) and the inferior parietal lobule (involved in the maintenance of representations and in working memory). The contribution of this network has been related to RHM's conjecture of lexical activation/inhibition, although Abutalebi and Green (2007) noted that the massive involvement of control processes does not fit well with the clear separation made in RHM between the lexicons of L1 and L2 (see also below). The importance of language control further became clear in neuropsychological research, as it was observed that asymmetric language recovery in bilinguals (i.e., better/faster recovery in L1 or - sometimes - in L2) depended more on access to the information rather than on the loss of the inaccessible information (see Fabbro, 1999, for a review). Control issues could also be seen in cases of pathological language switching and mixing after brain injury, when the patients were no longer able to make a distinction between their languages.

Another technique in cognitive neuroscience is ERP (Event-Related Potentials) research. This technique has a better temporal resolution than brain imaging (with millisecond resolution) but a worse localization potential. One of the first studies using this technique and referring to the RHM model reported evidence in favor of the model (Rodriguez-Fornells, Rotte, Heinze, Nosselt and Münte, 2002). These authors asked Catalan-Spanish bilinguals and Spanish monolinguals to press a button when presented with Spanish words, while ignoring pseudo-words and Catalan words. Rodriguez-Fornells et al. (2002) observed that the brain potentials of the bilinguals in response to the Catalan words were not affected by the frequency of these words, suggesting that these letter strings were not recognized as existing words. The authors saw this finding as evidence in line with the predictions of RHM (however, see below).

\section{Questions about the Revised Hierarchical Model}

In the present section we discuss five lines of research that constitute challenges for the classical RHM.

\section{Evidence against separate lexicons and selective access}

A first problem with the RHM is that there is little direct evidence for separate L1 and L2 lexicons. As a matter of fact, there is good evidence AGAINST the assumption: L1 lexical representations influence the recognition of L2 words and vice versa (though to a lesser degree). Given that other summaries of the evidence exist (e.g., Brysbaert, 1998; Brysbaert and Dijkstra, 2006), we only list some of the most convincing findings here.

In the domain of spoken word recognition, Spivey and Marian (1999) investigated whether Russian-English bilinguals would be influenced by L2 knowledge while listening to L1 target words and instructions. They made use of the so-called "visual world paradigm". In this paradigm participants see a few familiar objects (e.g., a candy, an apple, a candle and a fork) and are asked to perform an action on one of them (e.g., "pick up the candle"). The eye movements are tracked to see which objects the participants fixate. Under these circumstances, participants quite often briefly look at the candy before they look at the candle. This interference effect is consistent with the cohort model of auditory word recognition (Marslen-Wilson, 1987), according to which all words starting with the same initial sounds are activated at first and are subsequently pruned as more information reaches the brain. Given that both candle 
and candy start with the same sounds, for some time they compete with each other. Spivey and Marian (1999) examined whether a similar competition effect would be observed across languages. They gave Russian-English bilinguals the L1 instruction Poloji marku nije krestika" "Put the stamp below the cross". One of the distracter items was a marker (named flomaster in Russian). For the bilingual participants in the experiment this was an L2 competitor of the target word marku "stamp". Spivey and Marian reported that participants indeed regularly looked at the marker before they picked up the stamp, suggesting that the L2 names of the objects had been activated, even though the $\mathrm{L} 2$ was not involved in or crucial for the experiment. This finding was later replicated in several studies by Marian and colleagues (Marian and Spivey, 2003; Marian, Blumenfeld and Boukrina, 2008; Marian, Spivey and Hirsch, 2003), and by Weber and Cutler (2004), although the last only observed an effect of L1 distracters on L2 targets and not vice versa.

Evidence against language-selective access in visual word recognition was reported by Dijkstra, Timmermans and Schriefers (2000). They presented Dutch-English bilinguals with lists of English and Dutch words and asked the participants to press a button if an English word appeared. If the presented word belonged to the Dutch language, they were instructed to wait for the next word (i.e., a go/no-go paradigm). Dijkstra et al. were particularly interested in the comparison between words that only exist in English (e.g., home) and words that exist both in English and in Dutch but have a different meaning in the two languages (so-called interlingual homographs, such as room, which means "cream" in Dutch). The idea was that if participants were able to deactivate their Dutch lexicon, they should not be influenced by whether or not the letter string formed a word with a different meaning in Dutch. Still, Dijkstra et al. obtained a reliable homograph effect: participants needed more time to decide that a homograph was an English word $(657 \mathrm{~ms})$ than that a non-homograph was an English word $(577 \mathrm{~ms})$, even though the frequency of the homograph was much higher in English than in Dutch and even though all test words were readily recognized as valid English words (more than 97\% correct responses).

Even more interesting in Dijkstra et al. (2000) was the finding that the interlingual homograph effect in visual word recognition was observed not only in L2 performance but also in L1 performance. When the participants were asked to press on a button when the letter string formed a word in Dutch and to refrain from responding when it was a word in English, Dijkstra et al. also obtained a reliable homograph effect. Participants took longer to accept a letter string as an existing word in their mother tongue when it was an English homograph (room) than when it was not (e.g., nis "niche"). The effect was particularly strong (over $200 \mathrm{~ms}$ ) when the homograph was more frequently used in English than in Dutch (as is the case for room), but still amounted to $31 \mathrm{~ms}$ for homographs that had a higher frequency in Dutch than in English (e.g., hoop "hope" vs. mond "mouth").

Other strong evidence for the influence of foreign language knowledge on native language performance was reported by van Hell and Dijkstra (2002). These authors asked trilinguals with Dutch as their native and dominant language (L1), English as their second language (L2) and French as their third language (L3) to take part in a Dutch lexical decision task. The L1 stimulus words were cognates with their translations in English, cognates with their translations in French or non-cognates. Van Hell and Dijkstra observed faster response times to L1 words that were cognates with L2 than to the non-cognates, even though nothing in the context referred to the English language. Furthermore, they observed an additional effect of cognateness with French (L3) if the participants were equally fluent in English and in French. On the basis of these findings, the authors concluded (p. 780): "The results indicate that words presented in the dominant language, to naive participants, activate information in the nontarget, and weaker, language in parallel, implying that the multilinguals' processing system is profoundly nonselective with respect to language. A minimal level of nontarget language fluency seems to be required, however, before any weaker language effects become noticeable in L1 processing." Notice that the cognate facilitation effect in proficient bilinguals is also in conflict with some of the evidence Kroll and de Groot (1997) listed for the developmental hypothesis (see above). Cognates are easier to recognize not only in the first stages of L2 acquisition (when the word-word associations are thought to be most important), but also in proficient L2 speakers (when conceptual mediation is assumed to be strong).

To investigate whether interactions between the languages of a bilingual are limited to isolated word recognition, Duyck, van Assche, Drieghe and Hartsuiker (2007) presented Dutch-English cognates (such as cat) and matched control words (such as bag) in sentences that participants had to read for understanding while their eye movements were monitored. Duyck et al. (2007, Experiment 3) observed significantly shorter fixation durations on the cognate words than on the control words, in line with the hypothesis that L1 representations are activated whenever they match the L2 input, even when the entire linguistic, semantic and syntactic context of the words is L2. This shows that even the language of a sentence is not used as a cue for language-selective lexical access (see also the findings of Spivey and Marian (1999), discussed above, for evidence with spoken word recognition). Interestingly, the very same cognate effect has recently been observed in an eye-tracking experiment when participants were reading L1 sentences (van Assche, Duyck, Hartsuiker and Diependaele, 2009). 
In the section on neurocognition, we saw how the initial findings in cognitive neuroscience seemed to agree with RHM. This is no longer true for more recent studies that, inspired by the behavioral studies, focused on main effects predicted by cross-language interactions rather than on null-effects compatible with RHM. An example of this type of study is Thierry and $\mathrm{Wu}$ (2007), who examined fifteen late fluent Chinese-English bilinguals. Participants were asked to indicate whether a word pair was semantically related (post-mail) or not (train-ham). Half of the word pairs (both related and unrelated) shared a character in the Chinese orthography (e.g., the Chinese translations of train and ham, Huo Che and Huo Tui, share a character); the other word pairs did not share a character in their translations. Although the complete experiment was run in English and no reference was made to Chinese, Thierry and Wu (2007) observed differences in the ERP signal between trials with shared characters and trials without such characters, indicating that the Chinese translations had been activated.

Van Heuven, Schriefers, Dijkstra and Hagoort (2008) asked late Dutch-English bilingual participants to take part in an English lexical decision task. Half of the word stimuli were pure English words, half were interlingual homographs (e.g., room). As before, the authors observed a reliable homograph interference effect in the reaction times, showing that $\mathrm{L} 1$ representations were active during L2 word recognition. At the same time, the participants' brains were scanned to see which brain areas were involved. The authors observed enhanced activity for the homographs in the left inferior prefrontal cortex, in the pre-supplementary motor area, the anterior cingulate cortex, the left inferior parietal lobule and the left precuneus. Interestingly, when the authors repeated the study with a generalized lexical decision task, in which the participants were required to press "yes" whenever a presented letter string was a word, irrespective of the langue to which it belonged (L1 or L2), they no longer observed a difference in RT to the homographs and the control words, but still found enhanced activity in two parts of the left inferior prefrontal cortex for homographs. These regions are typically associated with phonological and semantic processing, making van Heuven et al. conclude that bilinguals cannot suppress language interference at the neuronal level, even when no overt effects are observed at the behavioral level.

It might be argued that the evidence reviewed thus far provides evidence against language selective access, but not against RHM's assumption of separate lexicons. It could be that there are two different lexicons, activated in parallel by the sensory input. Although the issue of separate lexicons with parallel access vs. a unitary lexicon with parallel access is very difficult to decide empirically, van Heuven et al. (1998) reasoned that evidence could be obtained by looking at word form interactions during visual word recognition. If it can be shown that word forms of one language do not interact with those of the other language as part of lexical access, then that would be good evidence for at least functionally separated lexicons. On the other hand, if the word forms of the non-target language interact in very much the same way as the word forms of the target language, then that would be good evidence for an integrated lexicon.

Van Heuven et al. (1998) made use of the finding that visual word recognition is affected by the number and the characteristics of orthographically similar words (the so-called orthographic neighbors). The recognition time of the word lame is influenced by the fact that there are seventeen very similar words in English (dame, fame, game, lace, lade, lake, lama, lamb, lamp, lane, late, lave, laze, lime, name, same, tame) and that some of these words are more frequent than lame (e.g., the frequency of lame is 11 per million words, whereas that of same is 417 per million words; Brysbaert and New, 2009). The existence of many orthographically similar words gives a letter string a more word-like feeling (making it easier to press "yes" in a lexical decision to a word with many orthographic neighbors, and more difficult to press "no" to a nonword with many orthographic neighbors), but at the same time hinders the identification of the word itself, in particular when some of the orthographic neighbors are more frequent (Grainger and Jacobs, 1996). This is because in written word recognition the visual input not only activates the word that is presented but also the words that resemble the input. The different representations then compete with each other, until the activation level of the word representation that corresponds to the input clearly dominates the activation levels of the other, resembling words. Van Heuven et al. (1998) reasoned that if L1 and L2 have different lexicons, no effect would be observed of orthographic neighbors from the other language. So, the recognition of the English word lame by a Dutch-English bilingual would not be influenced by the fact that it also resembles the Dutch words dame, lamé, name, lome, lade, lage, lama, lamp and lams (some of which are English neighbors as well). However, this is not what van Heuven et al. (1998) observed: they found clear effects due to the number of neighbors in the non-target language, indicating that word representations of different languages compete with each other in very much the same way as word representations within a language. Although in principle such interactions could still be postulated between two separated lexicons, realistically this position does not seem to make sense. A single, integrated lexicon is a much more parsimonious explanation.

All in all, the picture emerging from the above (and related) research is that of L1 and L2 words acting very much as if they are words of the same language, interacting with each other as part of the word identification process. 
This is very different from the separate lexicon view of RHM, as also acknowledged by Kroll in some articles (e.g., Kroll and Dijkstra, 2002).

\section{Evidence against strong lexical connections between $L 2$ and $L 1$ words}

A second challenge for the RHM is that it predicts a solid translation priming effect from L2 words to L1 targets, given the strong lexical connections between L2 words and their L1 translations. Unfortunately, the evidence here is very meager (see Schoonbaert, Duyck, Brysbaert and Hartsuiker (2009) for a comprehensive review). Much of the evidence is based on the masked priming technique. In this technique, a prime is presented before the target for such a short period of time (typically $50-80 \mathrm{~ms}$ ) that it is not perceived consciously. Still, the prime has an effect on the target since associatively related primes induce faster target processing than unrelated primes.

Whereas it is no problem to find translation priming from L1 primes to L2 targets with masked priming, it is nearly impossible to find any translation priming at all from L2 to L1, certainly if the orthographies of the primes and the targets differ (see, e.g., Gollan, Forster and Frost (1997) with Hebrew-English bilinguals; Jiang (1999) and Jiang and Forster (2001) with ChineseEnglish bilinguals). Masked translation priming can be observed when the primes and the targets share the same alphabet, but unless the bilinguals are balanced the effect is significantly smaller than forward translation priming (see, e.g., Duyck and Warlop (2009) and Schoonbaert et al. (2009) with Dutch-English bilinguals).

A further intriguing finding was published by Jiang and Forster (2001). They noticed that when Chinese-English bilingual participants had to perform a lexical decision task, there was a robust priming effect of translation equivalents from Chinese L1 primes on English L2 target performance but no priming effect from English L2 translations on Chinese L1 targets. However, when the task was changed and participants had to indicate whether they had seen the target words before in a study phase (i.e., an episodic memory task), the pattern of results completely reversed: now there was a strong priming effect from L2 to L1, but not from L1 to L2. On the basis of these findings, Jiang and Forster (2001) ventured that the nonsemantic links between L2 and L1 words are not lexical links but episodic links, on par with what participants learn when they have to study lists of unrelated word pairs (e.g., when participants have to study lists of word pairs such as as day-woman or fairy-shark, and subsequently must produce the second word upon getting the first as a cue). In situations of paired associate learning, Jiang and Forster (2001) argue, no direct links are made between the lexical representations of the words in the word pair, but only indirect links mediated by associations in episodic memory (i.e., the memory for context-sensitive encounters with stimuli).

Excitatory lexical links between words in L1 and L2 are problematic for another reason as well. One of the main challenges in word recognition is to select the correct lexical representation on the basis of the sensory input. As we saw above, usually this is achieved through a process of competition between all the candidates that resemble the input to some degree (e.g., see McClelland and Rumelhart's (1981) Interactive Activation Model, or Dijkstra and van Heuven's (2002) bilingual extension of it). In many computational models (and certainly those that have a gradual build-up of activation), the competition is captured by inhibitory connections between the nodes in a layer (e.g., the words in the lexicon). In this way, a situation is prevented in which a number of nodes mutually reinforce each other through a positive feedback loop, so that they start to dominate the activation buildup and get selected even though they do not agree with the perceptual input. Although excitatory withinlayer connections are not forbidden in computational models, they tend to be avoided, certainly within the interactive-activation framework that currently dominates computational models of word recognition (an exception is Dell's (1986) model of word PRODUCTION). Therefore, if L1 and L2 words are part of the same lexicon (see the first issue), the conjecture of excitatory connections between them may result in quite harmful consequences for word recognition, in particular for low-frequency words.

\section{Word recognition and translation involve more than simple one-to-one mappings}

RHM is appealing because of the simplicity of the processes involved. Words are recognized, activate their meaning and their cross-language equivalents, and that is it. However, as soon as researchers attempt to implement the various assumptions in a working model or start to assess the detailed processes of word recognition and translation, they are confronted with the fact that the simple ideas behind RHM pose serious implementation problems.

In the previous section we already discussed the issue of excitatory lexical connections. This problem is further exacerbated by the fact that many translations are not simple one-to-one mappings (as acknowledged by, for instance, Tokowicz and Kroll, 2007). In particular, abstract words tend to have multiple translations depending on the context. But concrete words also often have different meanings (e.g., bank referring to money or to a river) or different senses (e.g., there is a chicken on the road vs. there is chicken in the fridge), which may require distinct translations. In addition, words have synonyms, as do their translations. The end result is that the excitatory lexical connections in RHM are not limited 
to a small set of one-to-one mappings, but start to form a quite intricate network of connections likely to impede correct processing of the perceptual input (remember that the main task of the lexicon is to activate the lexical representation corresponding to the perceptual input).

Another example of how real-life language use complicates the tenets of RHM is the finding that the reading of written words is not entirely based on the orthographic code, but involves the phonological code as well (Grainger, Kiyonaga and Holcomb, 2006; Rastle and Brysbaert, 2006; see also Ziegler \& Ferrand (1998) for evidence that the orthographical code contributes to the recognition of spoken words). This can be concluded from the finding that a target word (e.g., brain) is more efficiently processed when it has been preceded by a briefly presented homophonic prime (brane) than when it has been preceded by a control prime that does not sound the same (brank). Again, this feature of language processing involves more than a simple "augmentation" of RHM by making a distinction between an orthographic and a phonological lexicon in L1 and L2. For instance, many words are homophones (e.g., son vs. sun), further increasing the number of lexical representations that are activated on the basis of lexical connections, even when they are presented visually. In addition, there is evidence that the phonological recoding of written words happens automatically and in a languageindependent way (Brysbaert, van Dyck and van de Poel, 1999; van Wijnendaele and Brysbaert, 2002; Duyck, 2005). This means that the written English word peer for a Dutch-English bilingual not only activates the phonology of its English homophone pier, but also the phonology of the Dutch word pier, which means both "pier" and "worm". In addition, peer is a Dutch word as well, meaning "pear" (a homophone of pair). Examples such as these show how easily information would spread through the lexicons if the RHM were implemented. In this respect it is important to keep in mind that the example given is by no means an exception, certainly not for languages with a common origin such as English and Dutch.

\section{The RHM underestimates the importance of conceptual mediation in L2 understanding and backward translation}

A fourth issue on which the RHM has been challenged concerns the assumption of limited conceptual mediation in L2 word understanding and translation. Only for very high levels of proficiency does the model assume equivalent conceptual mediation in L2 and L1.

Already in the year of RHM's publication, de Groot, Dannenburg and van Hell (1994) published an article in which they questioned the limited involvement of semantics in L2 processing. They asked participants to translate words from L1 to L2 (forward) or from L2 to L1 (backward), and observed that very much the same variables predicted translation performance in each direction. In their own words: "meaning played a somewhat more important role in forward than in backward translation, whereas familiarity appeared to have a larger influence in backward translation. A few other differences between forward and backward translation were detected, but, when considering the complete stimulus set, the differences between translation directions were generally small" (de Groot et al., 1994, p. 600). Importantly, these were not data from balanced bilinguals, as could be assumed from the developmental hypothesis of RHM, but from unbalanced bilinguals with limited fluency in their second language. Even for them, conceptual mediation played a significant role in $\mathrm{L} 2-\mathrm{L} 1$ translation.

Converging findings were published by La Heij, Hooglander, Kerling and van der Velden (1996). Using a bilingual Stroop task (Experiment 1), they reported that congruent color words (for which the ink color corresponded to the word) were translated faster than incongruent color words both in forward translation (as predicted by RHM) and in backward translation. In addition, they found that translation of words (e.g. chair) was faster in the presence of a semantically related picture (e.g., of a table) than in the presence of an unrelated picture. Again this was true for both directions of translation (La Heij et al., 1996, Experiments 3, 4 and 5; see also Bloem and La Heij, 2003).

Duyck and Brysbaert (2004) addressed the issue of asymmetric conceptual mediation with numerical stimuli. They made use of the finding that the time needed to understand numbers depends on the magnitude of the number: participants need more time to read large numbers (e.g., 9, 12) than small numbers (e.g., 1, 4). Duyck and Brysbaert examined whether this finding would result in a number magnitude effect when participants were asked to translate numbers. They indeed obtained such an effect, both in forward translation AND in backward translation, indicating semantic access during L2 word translation (for similar results in backward translation from L3, see Duyck and Brysbaert, 2008). Importantly, these effects were observed even when using a set of newly learned number words (a so-called foreign language), which the participants acquired only one hour before testing. On the basis of these findings, Duyck and Brysbaert (2004) hypothesized that when there is a complete overlap of meaning between L1 and L2 words, new L2 words are not acquired through lexical connections or episodic connections, but by early mapping of L2 word forms to meaning (see de Brauwer, Duyck and Brysbaert (2008) for a similar conclusion based on another number processing task).

Duyck and de Houwer (2008) further tested the issue of semantic mediation in L2 word processing by asking unbalanced bilinguals to perform a semantic 
Simon task on L2 words. In this task, participants have to say one response (e.g., "animal") when the word stimuli are written in capitals and another response (e.g., "occupation") when the stimuli are written in lowercase letters. Semantic activation of the word stimuli is measured by comparing congruent trials (i.e., saying "animal" to LION or "occupation" to lawyer) with incongruent trials (saying "occupation" to lion and "animal" to LAWYER). Even though the meaning of the stimulus words was irrelevant for the task at hand, Duyck and de Houwer (2008) observed a congruency effect both in L1 and in L2, yielding support for fast and automatic semantic access during L2 word processing.

Evidence along the same lines was also reported by Sunderman and Kroll (2006). They used the translation verification task and asked English-Spanish bilinguals whether Spanish-English word pairs were each other's translation or not - for example, cama-bed ("yes"), cama-scholar ("no"). There were two types of no-trials: trials with semantically related words (cama-blanket) and trials with unrelated words of the same length and frequency as the related words (cama-scholar). Sunderman and Kroll (2006) observed that participants took longer to say "no" to the trials with semantically related words (cama-blanket) than to trials with unrelated words (cama-scholar) at all tested proficiency levels. This finding converges with the previously mentioned findings showing that meaning activation is an essential component of L2 word recognition, even at low proficiency levels.

\section{Is all conceptual information language independent?}

Finally, it may be wondered to what extent all semantic information is language-independent, as suggested by the RHM. Paradis (1997), for instance, does not think so. In his three-store hypothesis there are three levels of representation: lexical, semantic and conceptual. The first two levels are language-dependent; only the last one is shared by all the languages known to a multilingual. Paradis (1997) opted for a language-dependent semantic store because of language constraints on the meaning of words. As an example, he mentioned the fact that in English you cannot say a large sister instead of a big sister, whereas it is perfectly possible to talk about $a$ large book when you refer to a big book. According to Paradis, this type of subtlety cannot be represented by a language-independent semantic system. Therefore, he made a distinction between lexical meaning (which is part of the speaker's linguistic competence in a language) and conceptual representation (which exists outside language and remains intact in aphasia).

Evidence for the idea that information is not stored completely in a network of language-independent concepts can be found in the memory literature, where it has been found that memory retrieval depends on the availability of language cues to activate the appropriate memory traces. For instance, Sahlin, Harding and Seamon (2005) presented a list of 120 words at a speed of one word per 3 seconds to prolific English-Spanish bilinguals. The participants were asked to memorize the words for a subsequent memory test. Half of the words were in English, half in Spanish. In the memory test, participants received 96 words and had to indicate whether they were part of the studied words (independent of language) or not. The proportion of correctly memorized words learned in Spanish and presented in Spanish during the memory test was $88 \%$; for the English-English condition, the percentage was $85 \%$ (confirming that the participants were balanced bilinguals). However, percentage recognition was only $13 \%$ in the Spanish-English condition and 17\% in the English-Spanish condition. So, there was a huge memory cost for conditions in which the language cue of the encoding could not be used in the retrieval, suggesting that the information had not been stored in a languageindependent way.

The importance of language cues is also well documented in autobiographical memory. Marian and Neisser (2000) asked Russian immigrants in the US to discuss the first autobiographical memory that came to mind upon hearing a target word. When the interview language was Russian, significantly more memories from a Russian context were retrieved than memories from an English context. The reverse was true when the interview language was English. In a second experiment, the authors showed that both the language of the interview and the language of the target words had an impact. Although, strictly speaking, these results are limited to the autobiographical episodic memory, Marian and Neisser ventured that very much the same effects would be observed in semantic memory.

Later versions of RHM include the possibility of different degrees of meaning overlap between L1 and L2 translation equivalents. These versions incorporated the Distributed Feature Model of de Groot and van Hell (de Groot, 1992; de Groot et al., 1994; van Hell and de Groot, 1998). According to this model, word meanings are represented as sets of features and the overlap in meaning of two translations is indexed by the number of features that are shared. For instance, de Groot and colleagues argued that concrete words (e.g. "ball") have more similar meanings in L1 and L2 (indicated by a larger feature overlap) than abstract words (e.g. "justice"). This is based on the assumption that the functions of the objects to which concrete words refer are quite similar across languages and cultures. In contrast, because abstract words tend to be used in different contexts across languages, they will be less similar in meaning. Evidence for this theory comes, for example, from de Groot (1992), who observed faster translation production and recognition responses to concrete words than to matched 
abstract words. A main challenge for the Distributed Feature Model is to explain how it scales up from single words to discourse propositions, which arguably is how many verbal memories are stored.

\section{The alternative}

As indicated above, the body of research inspired by RHM has yielded findings that question important tenets of the model. To summarize:

(1) There is little evidence for separate lexicons.

(2) There is little evidence for language selective access.

(3) Including excitatory connections between lexical translation equivalents risks impeding word recognition.

(4) The connections between L2 words and their meanings are stronger than proposed in RHM.

(5) It may be necessary to make a distinction between language-dependent and language-independent semantic features.

It is not clear to us how RHM, as it is currently formulated (see Figure 1), can be adapted to incorporate all the challenges listed above. One way forward may be to effectively try to implement the various ideas in a working model (rather than the current generic, boxesand-arrows version of the model) and see which changes are needed for RHM to integrate the conflicting findings discussed in this article. For instance, it may be that the current excitatory connections between the lexicons can no longer be retained, because they hinder word perception (as indicated above). An alternative suggested by Duyck and Brysbaert (2004) is that most priming effects can be explained by assigning proper weights to the connections between the lexical and the conceptual level. Schoonbaert et al. (2009) showed how the lower level of translation and semantic priming from L2 to L1 than the other way around can be explained in RHM by changing the current version of the model into a Distributed Feature Model in which L2 words activate fewer semantic nodes than L1 words (see Figure 2). The implementation of the various suggestions would make clear what their strengths and weaknesses are.

Another, possibly even more advantageous, way forward would be to start from an existing computational model of monolingual word processing and see how this model can be augmented with L2 information. Rather than starting from intuitions about what a bilingual memory may look like, we could examine how an existing model of monolingual word processing changes when it additionally receives input from another language (either simultaneously with L1 or sequentially). Indeed, such an approach has been pioneered successfully by Dijkstra, Grainger and van Heuven.

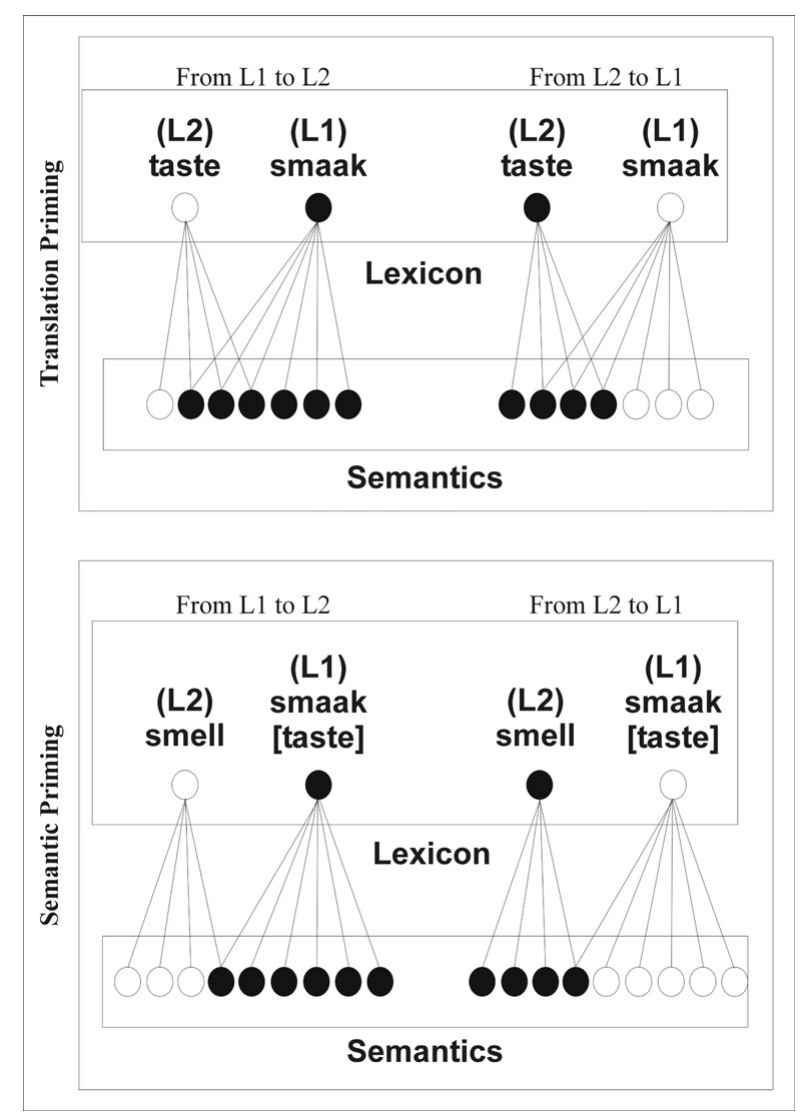

Figure 2. Model to explain less semantic and translation priming from L2 on L1 than the other way around. Rather than assuming that translation priming is due to direct activation links between lexical translation equivalents, as the RHM does, this model assumes that translation priming, just like semantic priming, is semantically mediated. L1 words have richer semantic representations than L2 words (i.e., they activate more semantic features). As a result, L1 primes activate a large percentage of the semantic nodes connected to L2 targets, whereas L2 primes only activate a small section of the semantic nodes connected to L1 targets. This model correctly predicts the different effects found in forward and backward translation and semantic priming (Schoonbaert et al., 2009).

First, they presented the Bilingual Interactive Activation (BIA) model of visual word processing, shown in Figure 3 (Dijkstra, van Heuven and Grainger, 1998; van Heuven et al., 1998). This model was a straightforward extension of the IA-model of visual word recognition, first proposed by McClelland and Rumelhart (1981). The model contained the three layers used by McClelland and Rumelhart (features, letters and words), added L2 words to the word layer and a language layer at the top. This model could simulate many of the L1-L2 interactions in visual word recognition presented in this article, and is particularly valuable because of the detailed assumptions and predictions that it makes about cross-lingual lexical interactions. 


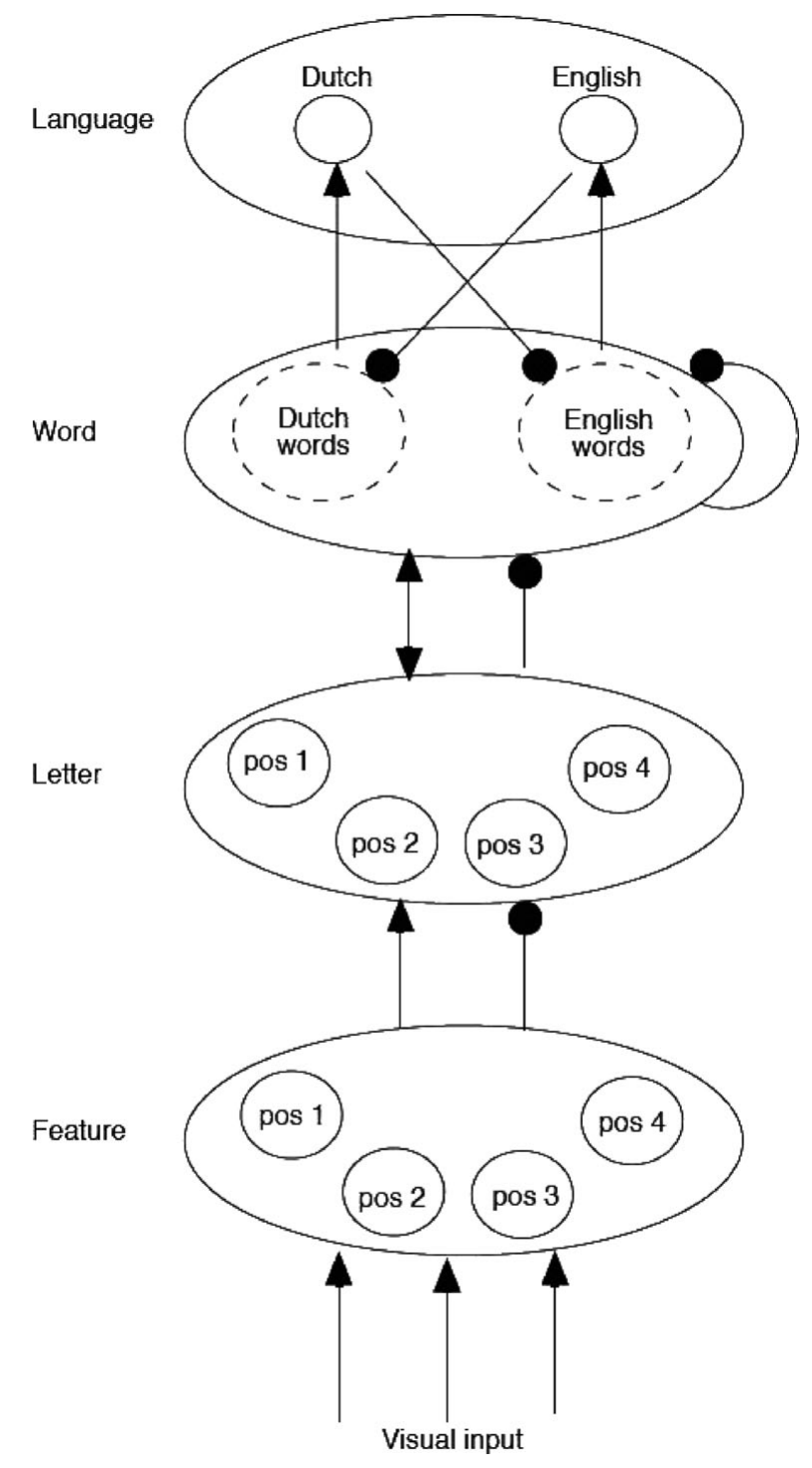

Figure 3. The Bilingual Interactive Activation model. The BIA model is an example of how an existing computational model of monolingual language processing can be adapted to include input from two languages. It starts from McCelland and Rumelhart's Interactive Activation model for English word recognition and adds nodes to the word level for Dutch L2 input. It additionally had a fourth layer containing two language nodes. Arrowheads indicate excitatory connections; black circles indicate inhibitory connections. Notice that in this model there no longer are excitatory connections at the word levels between L1 and L2 translation equivalents (van Heuven et al., 1998).

Because the BIA model was limited in many respects (e.g., it did not include semantic information or phonological information), and because some data were not fully in line with BIA, Dijkstra and van Heuven (2002) later presented the $\mathrm{BIA}+$ model (Figure 4). This model also made a distinction between a word identification system and a task decision system to capture the fact

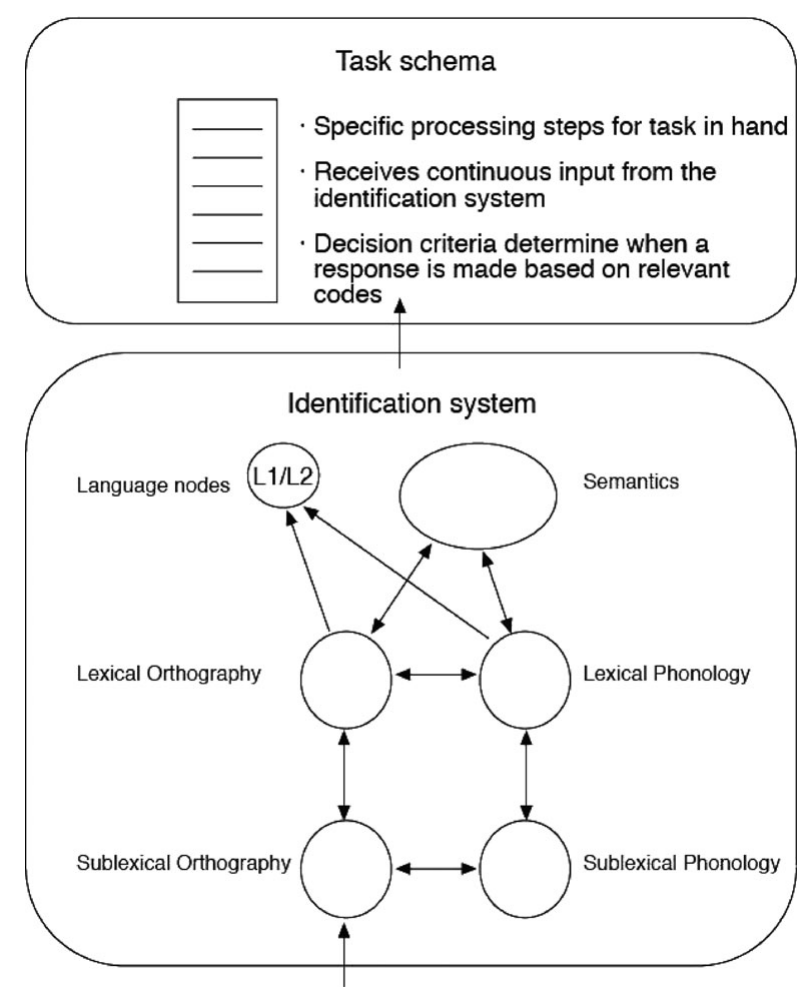

Figure 4. The BIA+ model. The BIA + model is an upgrade of the original BIA model. Next to orthographic information, it includes phonological and semantic information. In addition, a distinction is made between the word identification system and the ways in which the information is subsequently used as a function of the task context (i.e., what the bilingual has to do) (Dijkstra \& van Heuven, 2002).

that the outcome of a bilingual word identification system is controlled in various ways by the context in which the language processing occurs (e.g., when participants are asked to respond only to words of one language).

Computational modeling of monolingual word processing is an evolving field. As a result, there are other, more detailed, models around than McClelland and Rumelhart's IA (e.g., Coltheart, Rastle, Perry, Langdon and Ziegler, 2001; Harm and Seidenberg, 2004; Perry, Ziegler and Zorzi, 2007). A challenge will be to see how these models can be adapted so that they are able to recognize and translate words from more than one language, and how performance of these models alters as a function of the proficiency level. These, we think, are the real challenges ahead of us, rather than a stream of many more experiments testing the assumptions of RHM.

\section{References}

Abutalebi, J. \& Green, D. (2007). Bilingual language production: The neurocognition of language representation and control. Journal of Neurolinguistics, 20, 242-275. 
Altarriba, J. (1990). Constraints on interlingual facilitation effects in priming in Spanish-English bilinguals. Unpublished dissertation, Vanderbilt University.

Belke, E. \& Meyer, A. S. (2005). Refractory effects in picture naming as assessed in a semantic blocking paradigm. Quarterly Journal of Experimental Psychology, 58A, 667692.

Bloem, I. \& La Heij, W. (2003). Semantic facilitation and semantic interference in word translation: Implications for models of lexical access in language production. Journal of Memory and Language, 48, 468-488.

Brysbaert, M. (1998). Word recognition in bilinguals: Evidence against the existence of two separate lexicons. Psychologica Belgica, 38, 163-175.

Brysbaert, M. \& Dijkstra, T. (2006). Changing views on word recognition in bilinguals. In J. Morais \& G. d'Ydewalle (eds), Bilingualism and second language acquisition. Brussels: KVAB.

Brysbaert, M. \& New, B. (2009). Moving beyond Kucera and Francis: A critical evaluation of current word frequency norms and the introduction of a new and improved word frequency measure for American English. Behavior Research Methods, 41, 977-990.

Brysbaert, M., van Dyck, G. \& van de Poel, M. (1999). Visual word recognition in bilinguals: Evidence from masked phonological priming. Journal of Experimental Psychology: Human Perception and Performance, 25, 137148.

Coltheart, M., Rastle, K., Perry, C., Langdon, R. \& Ziegler, J. (2001). DRC: A dual route cascaded model of visual word recognition and reading aloud. Psychological Review, 108, 204-256.

Damian, M. F., Vigliocco, G., \& Levelt, W. J. M. (2001). Effects of semantic context in the naming of pictures and words. Cognition, 81, B77-B86.

de Brauwer, J., Duyck, W. \& Brysbaert, M. (2008). The SNARC effect in the processing of second language number words: Further evidence for strong lexico-semantic connections. Quarterly Journal of Experimental Psychology, 61, 444458.

de Groot, A. M. B. (1992). Determinants of word translation. Journal of Experimental Psychology: Learning Memory and Cognition, 18, 1001-1018.

de Groot, A. M. B., Dannenburg, L. \& van Hell, J. G. (1994). Forward and backward word translation by bilinguals. Journal of Memory and Language, 33, 600-629.

Dell, G. S. (1986). A spreading-activation theory of retrieval in sentence production. Psychological Review, 93, 238-321.

Dijkstra, T., Timmermans, M. \& Schriefers, H. (2000). On being blinded by your other language: Effects of task demands on interlingual homograph recognition. Journal of Memory and Language, 42, 445-464.

Dijkstra, T. \& van Heuven, W. J. B. (2002). The architecture of the bilingual word recognition system: From identification to decision. Bilingualism: Language and Cognition, 5, 175197.

Dijkstra, T., van Heuven, W. J. B. \& Grainger, J. (1998). Simulating cross-language competition with the bilingual interactive activation model. Psychologica Belgica, 38, 177-196.
Duyck, W. (2005). Translation and associative priming with cross-lingual pseudohomophones: Non-selected phonological activation in bilinguals. Journal of Experimental Psychology: Learning, Memory, and Cognition, 31, 13401359.

Duyck, W. \& Brysbaert, M. (2004). Forward and backward number translation requires conceptual mediation in both balanced and unbalanced bilinguals. Journal of Experimental Psychology: Human Perception and Performance, 30, 889-906.

Duyck, W. \& Brysbaert, M. (2008). Semantic access in number word translation: The role of cross-lingual lexical similarity. Experimental Psychology, 55, 73-81.

Duyck, W. \& de Houwer, J. (2008). Semantic access in second-language visual word processing: Evidence from the semantic Simon paradigm. Psychonomic Bulletin \& Review, 15, 961-966.

Duyck, W., van Assche, E., Drieghe, D. \& Hartsuiker, R. (2007). Visual word recognition by bilinguals in a sentence context: Evidence for non-selective lexical access. Journal of Experimental Psychology: Learning, Memory, and Cognition, 33, 663-679.

Duyck, W. \& Warlop, N. (2009). Translation priming between the native language and a second language: New evidence from Dutch-French bilinguals. Experimental Psychology, $56,173-179$.

Fabbro, F. (1999). The neurolinguistics of bilingualism: An introduction. London: Routledge.

Glanzer, M. \& Duarte, A. (1971). Repetition between and within language in free recall. Journal of Verbal Learning and Verbal Behavior, 10, 625-630.

Goggin, J. \& Wickens, D. D. (1971). Proactive interference and language change in short-term memory. Journal of Verbal Learning and Verbal Behavior, 10, 453-458.

Gollan, T., Forster, K. L. \& Frost, R. (1997). Translation priming with different scripts: Masked priming with cognates and noncognates in Hebrew-English bilinguals. Journal of Experimental Psychology: Learning, Memory, and Cognition, 23, 1122-1139.

Grainger, J. \& Jacobs, A. M. (1996). Orthographic processing in visual word recognition: A multiple read-out model. Psychological Review, 103, 518-565.

Grainger, J., Kiyonaga, K. \& Holcomb, P. J. (2006). The time course of orthographic and phonological code activation. Psychological Science, 17, 1021-1026.

Green, D. W. (1998). Mental control and the bilingual lexicosemantic system. Bilingualism: Language and Cognition, $1,67-81$.

Harm, M. W. \& Seidenberg, M. S. (2004). Computing the meanings of words in reading: Cooperative division of labor between visual and phonological processes. Psychological Review, 111, 662-720.

Heredia, R. R. (2008). Mental models of bilingual memory. In J. Altarriba \& R. R. Heredia (eds), An introduction to bilingualism: Principles and processes, pp. 39-67. New York: Lawrence Erlbaum Associates.

Indefrey, P. (2006). A meta-analysis of hemodynamic studies on first and second language processing: Which suggested differences can we trust and what do they mean? Language Learning, 56, 279-304. 
Jiang, N. (1999). Testing processing explanations for the asymmetry in masked cross-language priming. Bilingualism: Language and Cognition, 2, 59-75.

Jiang, N. \& Forster, K. I. (2001). Cross-language priming asymmetries in lexical decision and episodic recognition. Journal of Memory and Language, 44, 32-51.

Keatley, C., Spinks, J. \& de Gelder, B. (1994). Asymmetrical semantic facilitation between languages. Memory \& Cognition, 22, 70-84.

Kroll, J. F. \& de Groot, A. M. B. (1997). Lexical and conceptual memory in the bilingual: Mapping form to meaning in two languages. In de Groot A. M. B. \& KrollJ. F. (eds), Tutorials in bilingualism: Psycholinguistic perspectives, pp. 201224. Mahwah, NJ: Lawrence Erlbaum Publishers.

Kroll, J. F. \& Dijkstra, A. F. J. (2002). The bilingual lexicon. In R. A. Kaplan (ed.), The Oxford handbook of applied linguistics, pp. 301-321. Oxford: Oxford University Press.

Kroll, J. F. \& Stewart, E. (1994). Category interference in translation and picture naming: Evidence for asymmetric connections between bilingual memory representations. Journal of Memory and Language, 33, 149-174.

La Heij, W., Hooglander, A., Kerling, R. \& van der Velden, E. (1996). Nonverbal context effects in forward and backward translation: Evidence for concept mediation. Journal of Memory and Language, 35, 648-665.

Marian, V., Blumenfeld, H. K. \& Boukrina, O. V. (2008). Sensitivity to phonological similarity within and across languages. Journal of Psycholinguistic Research, 37, 141170.

Marian, V. \& Neisser, U. (2000). Language-dependent recall of autobiographical memories. Journal of Experimental Psychology: General, 129, 361-368.

Marian, V. \& Spivey, M. (2003). Bilingual and monolingual processing of competing lexical items. Applied Psycholinguistics, 24, 173-193.

Marian, V., Spivey, M. \& Hirsch, J. (2003). Shared and separate systems in bilingual language processing: Converging evidence from eyetracking and brain imaging. Brain and Language, 86, 70-82.

Marslen-Wilson, W. D. (1987). Functional parallelism in spoken word-recognition. Cognition, 25, 71-102.

McClelland, J. L. \& Rumelhart, D. E. (1981). An interactiveactivation model of context effects in better perception, Part 1: An account of basic findings. Psychological review, 88, 375-405.

Meyers-Scotton, C. (2006). Multiple voices: An introduction to bilingualism. Malden, MA: Blackwell Publishing.

Paradis, M. (1990). Language lateralization in bilinguals: Enough already! Brain and Language, 39, 576-586.

Paradis, M. (1997). The cognitive neuropsychology of bilingualism. In A. M. B. de Groot \& J. F. Kroll (eds), Tutorials in bilingualism: Psycholinguistic perspectives, pp. 331-354. Mahwah, NJ: Lawrence Erlbaum Publishers.

Perry, C., Ziegler, J. C. \& Zorzi, M. (2007). Nested incremental priming in the development of computational theories: The CDP + model of reading aloud. Psychological Review, 114, 273-315

Rastle, K. \& Brysbaert, M. (2006). Masked phonological priming effects in English: Are they real? Do they matter? Cognitive Psychology, 53, 97-145.
Rodriguez-Fornells, A., Rotte, M., Heinze, H. J., Nosselt, T. \& Münte, T. F. (2002). Brain potential and functional MRI evidence for how to handle two languages with one brain. Nature, 415, 1026-1029.

Sahlin, B. H., Harding, M. G. \& Seamon, J. G. (2005). When do false memories cross language boundaries in EnglishSpanish bilinguals? Memory \& Cognition, 33, 14141421.

Schoonbaert, S., Duyck, W., Brysbaert, M. \& Hartsuiker, R. J. (2009). Semantic and translation priming from a first language to a second and back: Making sense of the findings. Memory \& Cognition, 37, 569-586.

Spivey, M. J. \& Marian, V. (1999). Cross talk between native and second languages: Partial activation of an irrelevant lexicon. Psychological Science, 10, 281-284.

Sunderman, G. \& Kroll, J. F. (2006). First language activation during second language lexical processing: An investigation of lexical form, meaning, and grammatical class. Studies in Second Language Acquisition, 28, 387422.

Thierry, G. \& Wu, Y. J. (2007). Brain potentials reveal unconscious translation during foreign-language comprehension. Proceedings of the National Academy of Science of the United States of America, 104, 12530 12535.

Tokowicz, N. \& Kroll, J. F. (2007). Number of meanings and concreteness: Consequences of ambiguity within and across languages. Language and Cognitive Processes, 22, 727-779.

van Assche, E., Duyck, W., Hartsuiker, R. J. \& Diependaele, K. (2009). Does bilingualism change native-language reading? Cognate effects in a sentence context. Psychological Science, 20, 923-927.

van Hell, J. G. \& de Groot, A. M. B. (1998). Conceptual representation in bilingual memory: Effects of concreteness and cognate status in word association. Bilingualism: Language and Cognition, 1, 193-211.

van Hell, J. G. \& Dijkstra, T. (2002). Foreign language knowledge can influence native language performance in exclusively native contexts. Psychonomic Bulletin \& Review, 9, 780-789.

van Heuven, W. J. B., Dijkstra, T. \& Grainger, J. (1998). Orthographic neighborhood effects in bilingual word recognition. Journal of Memory and Language, 39, 458483.

van Heuven, W. J. B., Schriefers, H., Dijkstra, T. \& Hagoort, P. (2008). Language confict in the bilingual brain. Cerebral Cortex, 18, 2706-2716.

van Wijnendaele, I. \& Brysbaert, M. (2002). Visual word recognition in bilinguals: Phonological priming from the second to the first language. Journal of Experimental Psychology: Human Perception and Performance, 28, 616627.

Weber, A. \& Cutler, A. (2004). Lexical competition in nonnative spoken-word recognition. Journal of Memory and Language, 50, 1-25.

Ziegler, J. C. \& Ferrand, L. (1998). Orthography shapes the perception of speech: The consistency effect in auditory word recognition. Psychonomic Bulletin \& Review, 5, 683689. 